\title{
Spontaneous secretion of lipoprotein lipase by bovine and ovine adipose tissue incubated for 7 days with or without insulin and dexamethasone
}

\author{
Y Faulconnier, Y Chilliard \\ INRA, Laboratoire Sous-Nutrition des Ruminants, 63122 St-Genès-Champanelle, France
}

The secretion of lipoprotein lipase (LPL) by adipose cells into the incubation medium differs with in vivo nutritional conditions, duration of incubation, and in vitro factors such as insulin, serum, heparin (Garfinkel et al, 1976, Bioch Biophys Acta, 424, 147-156 ; PradinesFiguères et al, 1988, Biochem Biophy Res Commun, 154, 982-990). The first objective of the present study was to measure the secretion of LPL activity by bovine and ovine adipose tissue (AT) explants incubated for 7 days (d) and to compare it to tissue LPL activity during the same duration of incubation. Moreover, the addition of insulin (INS) plus dexamethasone (DEX) to the incubation medium increased the tissue LPL activity (Faulconnier and Chilliard, 1995, Proc Nutr Soc, 54 (1), in press). So, the second objective was to study the effect of these two hormones on secreted LPL activity.

The LPL activities were studied on perirenal AT from non-lactating non-pregnant Holstein cows $(n=5)$ and ewes of the synthetic INRA-401 breed $(n=5)$, as described by Faulconnier and Chilliard (1995).

Explants of AT were taken at the time of slaughter, placed immediately at $37^{\circ} \mathrm{C}$ and cultured in sterile conditions with or without INS $(2 \mathrm{mU} / \mathrm{ml})$ and/or DEX (100 $\mathrm{nM})$ for $1,2,4$ and $7 \mathrm{~d}$. The culture medium was changed once daily. The daily secretion of LPL and the total tissue LPL extractable in detergent (tissue LPL) activities were measured at $37^{\circ} \mathrm{C}$ with an artificial emulsion containing $\left[{ }^{3} \mathrm{H}\right]$ triolein (Faulconnier et al, 1994, J Anim Sci, 72, 184-191).

In basal conditions the secreted LPL activity, at $24 \mathrm{~h}$ of incubation, tended to be greater in bovine than in ovine ( $38 \mathrm{vs} 16 \mathrm{nmol} / \mathrm{min}$ per $10^{6}$ adipocytes) AT, whereas initial tissue LPL activity was higher $(P<0.10)$ in ewes than in cows. This relatively important secretion of $L P L$ into the medium can partly explain the decrease in LPL activity observed between fresh AT (day 0 ) and explants after $24 \mathrm{~h}$ in vitro (Fauconnier et al, 1994).

Then secreted LPL activity decreased (-82 and $-69 \%$ in cows and ewes, respectively) between d 1 and 2 and remained low and stable from d 2 to $d 7$ in the two species.

The addition of INS plus DEX to the medium had no significant effect on secreted LPL activity whatever the incubation duration, whereas it significantly increased tissue LPL in the two species. INS or DEX alone did not change secreted LPL.

In conclusion, our results show that the general profile of secreted LPL by ruminant AT explants during $7 \mathrm{~d}$ of incubation in basal conditions was approximatively similar to that observed in tissue LPL during the same period, although secreted LPL activity was lower than tissue LPL. Moreover, the addition of INS plus DEX to the incubation medium did not change the rate of LPL secretion, whereas these hormones stimulated markedly tissue LPL activity.

\begin{tabular}{|c|c|c|c|c|c|c|c|c|}
\hline \multirow[b]{3}{*}{ Day } & \multicolumn{4}{|c|}{ Cowsa } & \multicolumn{4}{|c|}{ Ewesa } \\
\hline & \multicolumn{2}{|c|}{ Secreted LPL } & \multicolumn{2}{|c|}{ Tissue LPL } & \multicolumn{2}{|c|}{ Secreted LPL } & \multicolumn{2}{|c|}{ Tissue LPL } \\
\hline & Control & INS + DEX & Control & INS + DEX & Control & INS + DEX & Control & INS + DEX \\
\hline 1 & $\overline{38}$ & 51 & $\overline{\mathrm{nd}}$ & nd & $\overline{16}$ & $1 \overline{9^{b}}$ & nd & $\overline{n d}$ \\
\hline 2 & 7 & 14 & 34 & $70^{*}$ & 5 & $5^{b}$ & 36 & $86^{\star \star}$ \\
\hline 4 & 4 & 3 & 24 & $44^{*}$ & 2 & 4 & 23 & $63^{\star \star}$ \\
\hline 7 & 7 & 3 & 18 & 39 & 5 & 2 & 18 & $69^{\star}$ \\
\hline
\end{tabular}

a Initial (fresh AT, day 0 ) bovine and ovine LPL activity $=241$ and $331 \mathrm{nmoles} / \mathrm{min}$ per $10^{6}$ adipocytes, respectively ; ${ }^{*}{ }^{\star \star}$ : significant difference between control and INS + DEX, $P<0.05$, 0.01 , respectively ; $\mathrm{b}$ : value significantly lower $(P<0.10)$ in ewes than in cows ; nd: not determined. 